\title{
Research on the Development Mode of Rural Tourism
}

\author{
Liu Na \\ Yancheng Teachers University, School of Fine Arts and Design, Yancheng, Jiangsu, 224007
}

Keywords: rural tourism; driving force; Northern Jiangsu; tourism competitiveness

\begin{abstract}
By analyzing typical cases related to rural tourism at home and abroad, impetus source and driving force have been found in rural tourism development. Mechanisms have been established in driving rural tourism development on the basis of supply-side reform. According to the driving mechanism and the actual situation of the tourism in northern Jiangsu, problems have been diagnosed in driving forces and driving mechanisms and solutions have also been put forward on the rural tourism development, supply-side reform on driving source entity and its standard should be improved; mine features of rural tourism resources and its attractions should be enhanced; perfect the management system and elevate the service pulling force; establish the whole marketing idea and improve the marketing abilities of rural tourism.
\end{abstract}

\section{Introduction}

The tourism and economy development in the northern Jiangsu leaves behind the south, but the northern area of Jiangsu province is rich in rural tourism resources. The important factor of improving that entire competitiveness of tourism and regional and economic development in the northern Jiangsu is to make full use of rural tourism resources, strive to development rural tourism and establish hegemony development between the northern area and the southern area. Based on typical countries and typical cases of China related to rural tourism development, analysis has been made in driving force and mechanisms. For this, problems have been diagnosed in driving forces and driving mechanisms and solutions have also been put forward on the rural tourism development.

Typical cases of successful rural tourism development in China include Wuyuan Rural Tourism of Jiangxi Province, Yixing Fence Station Tourism, Xinghua Putian Rape Flower Tourism, Gaochun International Slow City Tourism of Jiangsu Province, Ningbo Cixi of Zhejiang Province and other family farms and village orders. The following is a choice of domestic rural tourism development and classic management cases to analyze the driving force of rural tourism development.

\section{Driving Force Analysis on Domestic Typical Cases of Rural Tourism}

The survey indicates that fence station mode of Yi Xing is co-founded by local people. They apply cooperative form in the process of planting agricultural products to rural tourism development to create the mode of agritainment association plus leading enterprises plus ordinary farmers. By starting participating in the business mode of fence station, "fence garden" can be used by farmers who have taken participation in the mode for free and some difficulties can be tackled on training, negotiation, advertising and network marketing. From this, agritainment association and leading enterprises play a critical role in united planning, united management and united marketing. Farmers who are weak, small and scattered and enterprises are united to run the mode to obtain the business target with scale, normalization and characteristics and enhance the operation and management competitiveness of agritainment.

Family farm orders tourism [1] is a behavior that family farmers develop diverse products of rural tourism and sign a time-bound travel consumption contract with consumer groups of city residents. The mode is superior to the rural tourism development mode. It classifies order tourism into four phases including information collection, contract signature, contract implementation and information feedback. Travel flow under the mode has strong requirement thrust and supply pulling 
force. Requirement thrust sources as follow: firstly, the current fruit and vegetable pesticides and fertilizer safety have always been a hot spot for the people, and family farms provide the people with a good solution to the problem. Secondly, from the perspective of the current participating population, families with children from kindergarten to primary school and retired families have a higher enthusiasm for family farms. The former cannot just experience the fun of parent-child travel, but also allow children to fully approach nature, feel the nature, experience the role of "little farmer" and fully learn the common sense of agricultural planting.

The "Ecological Journey" of Yaxi in Nanjing was officially awarded "International Slow City" at the Scottish International Slow City Conference on November 27, 2010, which means that a city form that slows down the pace of life has been established. Regulated by Cittaslow, awarded cities, villages and communities feature with less than 50 thousand seek for green lifestyle, anti-pollution and anti-noise and approve for urban greening and working by traditional ways, as well as give up displaying fast food court and big supermarket.

Gaochun International Slow City Tourism sticks to the idea of "Slow life" of International Slow City, stresses a relaxing and cozy lifestyle and the slow pace of free time. Depending on the unique charm of the town of Gaochun in the south of the Yangtze River, the city features a series of tourism ecological agricultural products, handicrafts, folk culture, food culture and beautiful landscapes and pastoral scenery. The mountains, water, city and forest are integrated. Tourist attraction is the image that drives the formation of tourist flows.

\section{Analysis on Driving Mechanism Based on Typical Mode of Rural Tourism}

Driving mechanisms that forming rural tourism flow is to form the tourism consumption demand under the combination of the tourist destination pull force and the demand source thrust. The decision on the time and space difference of the rural tourism flow is the destination supply-side driving force or the tourist destination pulling force and attraction. Based on the driving force analysis of typical cases of rural tourism at home and abroad and the characteristics of tourism economic activity system, the driving model of rural tourism supply side driving force is constructed. The supply-side driving force in the model is classified into four aspects: driving source power, rural tourism attraction, standardized tourism service pulling force and marketing planning and promotion. Among them, the driving source power is the driving source in the rural tourism supply-side tourism system. The reason why travel planning, standardized management system and the whole marketing planning and promotion can be established and competitive tourism attraction, service pulling force and marketing planning and promotion ability can be formed is that sustainable development of rural tourism is driven by impetus source, namely, powerful government, tourism association and leading enterprises.

In the view of supply-side reform, mechanisms driving rural tourism development as follow: firstly, give full play to the role of organizing, support and take the lead from local government, tourism association and lead enterprises and form the driving force for driving rural tourism systems. Secondly, tourism attractions are formed by driving their development planning by impetus force. At present, rural tourism attractions mainly include rural facilities, agricultural products with characteristics and production methods, as well as fresh and beautiful environment and local culture. Thirdly, the source of power drive, the implementation of quality certification system and standardized service system and other laws and regulations are formulated to regulate the formation of tourism services to pull the destination. Standardized tourism services include the formation of a unified and convenient reservation system, unified standard service facilities, unified standard service requirements and service monitoring system. Fourthly, the entire marketing and promotion of rural tourism products are driven by impetus source to create strong marketing ability. Fifthly, tourists form a tourism consumption perception effect after consuming tourism products, including the perception image, satisfaction and word of mouth formed on the destination. Perceived effects also influence the tourism consumption demand through feedback mechanisms. Sixthly, changes on tourism requirements mirror the situation of driving force. At this time, driving source entities 
(local government, tourism association and leading enterprises) take countermeasures based on the reflected information to further improve driving force in order to attract more visitors and create more tourism requirements.

\section{Countermeasures on Improving Tourism Competitiveness of Northern Jiangsu}

With rich material resources and leisure resources, economy in the northern Jiangsu develops rapidly and transportation becomes easier, which provide unique resources and traffic conditions for rural tourism development of the northern Jiangsu. The area is next to Yangtze River Belta region which features developing economy, dense population and bristling buildings, with huge market potential. However, rural tourism development in northern Jiangsu is generally characterized by weak and small dispersion, lack of driving force for rural tourism, single driving factor, lack of vitality, and no competition. To effectively promote competitiveness of rural tourism development, supply-side reform must be taken.

The survey shows that impetus entity of driving source has serious influence on the function playing. Government at all levels of northern Jiangsu should make a careful research, establish relevant organizations like hotel association of France and agritainment in the fence post of Yixing, coordinate relations between stakeholders in a special way and draw up regulations and requirements. Supervisory work should be made on it. Carry out unified planning and construction of products, unified brand planning, unified standard management and unified publicity and marketing; cultivate leading enterprises and take their leading role, improve the rural tourism driving mechanism, and strive to improve the driving power of rural tourism in northern Jiangsu.

Rural tourism attractions are the core of the products and the gist of purchase direction choices for tourists. Tourism attractions that are commercioganic are a precondition for sustainable development of rural tourism. Countries or cases with good sustainable development have special tourism attractions. In order to improve tourism attractions in northern Jiangsu, advices are as follow: 1 Tourism should be developed closely around the characteristics and advantages of the tourism resources of the respective rural areas in northern Jiangsu. 2 It is necessary to develop diversified tourism attractions for the characteristics of market segments, including sightseeing farms, education farms, family farms, and leisure farms. 3 Rural tourism attractions must highlight the characteristics of rural brands. 4 A rural tourism product certification system should be established and the management of rural tourism attraction quality certification should be strengthened.

Tourism service and attractions are the core content for products related to tourism. At present, low service management of rural tourism exists in northern area of Jiangsu province, the entire province and all the country, which is one of the important factors that lead to rural tourism weak and poor dispersion. All the regions in northern Jiangsu give play to the role of governments and relevant industries and associations, enact occupation standards, laws and regulations. They also train, supervise and manage service quality of the industry including standardized, united and simple booking system, service facilities, service requirements and monitoring. Pulling force on visitors from tourism service should be promoted.

It is hard for operating units to afford marketing fees because they are farmers or small companies. The comprehensive marketing ideas should be created for products marketing. Fees are paid by farmers who produce united goods and companies or local government. Driving source entities (government, industrial association and leading enterprises) are responsible for taking the lead action through unitedly planning and promoting the marketing, improving the marketing abilities and shaping brand image of rural tourism on the basis of the related conditions. Nowadays, there is few the comprehensive marketing of rural tourism in northern Jiangsu. Meanwhile, there are few famous rural tourism brands.

For marketing of rural tourism in northern Jiangsu, firstly the entire idea should be established. Secondly, Internet Plus model must be made full use of. With the rapid development of new media, plenty of information has been spread rapidly at different new medium, and most of them is related 
to brand image of tour destination, tourist satisfaction, public praises and complaint handling. The information exerts important impacts on how to choose tourist destination. Thirdly, market characteristics should be taken full advantage of. For example, tourist market mainly concentrates at short distance, with high revisiting rate, and marketing targets can refer to as residents living in the city with 1-3 hours' distance as choices, build database of tourist source to provide service on time.

\section{Conclusion}

Northern area of Jiangsu province, with relatively backward tourism and abundant village tourism resources, should view rural tourism development as an important link for the whole tourism and regard it as a new growth foe regional economic development. Driving force and mechanisms of rural tourism development should be raveled out. Meanwhile, exhausting ourselves to promoting driving force and improving driving mechanisms are required. Analyzing the driving force of rural tourism in typical developing countries and typical cases of China, the author considers that local governments, tourism association and leading enterprises play an important role in rural tourism development. Driven by this, rural tourism resources with characteristics can be mined and scientific planning on rural tourism attractions will be made. Relevant laws and regulations will be enacted. Services and management should be perfected and service pulling force should also be enhanced by establishing the comprehensive marketing idea and improving relevant abilities. Regional economic development can be accomplished via correlation driving effects while sustainable development is made in rural tourism of northern area of Jiangsu province.

\section{References}

[1] Sun Huaping, Xu Yang, Research on Tourism Development Mode Based on Rural Order of Family Farm [J], Theory Discussion, 2013(6):104 -107

[2] Chen Lixing, Liu Zhongquan. Crossing to Social Welfare: A New Perspective of Research on Social Welfare for the Aged in China [M]. Beijing: Social Science Literature Publishing House, 2007, 1: 7, 35.

[3] Han Junjiang. The New Study of Social Security and Social Welfare [M]. Changchun: Jilin People's Publishing House, 2015, 6: 247.

[4] Tao Yongmei. Construction and Risk Aversion of Risk Management Model in Private Colleges and Universities Based on System Theory [J]. Education and Vocation, 2015 (32): 22-26. 